been able to find the pycnidia of this form upon any of the specimens from the coast of Maine, south, though they are very abundant upon the fruiting stems of plants sent us by Miss Mounce from St. Andrews, and have been described by Dr. Petersen as very profuse in the Danish beds.

We could not discover the Labyrinthula in the longer, wider-leaf Zostera marina, L., from Nanaimo, Departure Bay, B.C., on the Pacific coast, though this grass was spotted and infested with a variety of other parasites. Despite their activities, the grass at Nanaimo was unusually abundant last year.

Charles E. Renn.

Woods Hole Oceanographic Institution, Woods Hole, Massachusetts, and

Department of Soil Microbiology,

N.J. Agricultural Experiment Station, New Brunswick, N.J.

I Renn, C. E., NATURE, 134, 416 ; 1934.

Cienkowski, L., Arch. Microscop. Anat., 3, 274; 1867.

3 Petersen, H. E., NATURe, 134, 143; 1934.

- Mounce, Report of Biological Board of Canada, 1933 ; Ottawa, 1934.

T'tutin, T. G., NATURE, 134, 573; 1934.

\section{Wasting Disease of Zostera marina}

THE variation in the width of the leaf of Zostera marina cannot be put down to any one particular cause. In common with all water plants, the size of the leaf is probably a reflexion of the nutritional balance in the plant itself, as is shown to be the case by Pearsall and Hanby ${ }^{1}$ for certain Potamogeton species.

Many of the circumstances enumerated by Dr. Cottam², such as reduced salinity, abnormal temperatures, short period of submergence, low light intensity, etc., by altering the nutritional balance, doubtless react to produce narrow-leaved plants.

That the production of the narrow-leaved plant is not a simple reaction is suggested by the fact that, in some places on the English coast, plants with leaves of all sizes grow mixed up together, while at other places, only Zostera marina var. angustifolia can be found, though the large-leaved type was abundant in 1921. Nor is the size of leaf a matter of age alone, for these narrow-leaved forms flower just as profusely as the broad-leaved plants.

All this goes to suggest that, in the disappearance of Zostera, one has to deal with a large number of circumstances and not with a single catastrophic event.

Fisheries Research Station,

R. W. ButChER.

Alresford, Hants.

March 6.

1 Pearsall and Hanby, New Phytologist, 24 ; 1925.

NATURE, 135, $306 ; 1935$.

\section{Fibre Saturation Point of Wood}

THE fibre saturation point of wood (f.s.p.), which is the minimum moisture content in equilibrium with a saturated atmosphere, is commonly estimated indirectly from the point at which $(a)$ shrinkage begins, or $(b)$ a sudden increase occurs in the compressive strength ${ }^{1,2}$, on lowering the moisture content from the green state. Though these methods agree fairly well in defining the f.s.p. of Sitka spruce as about
25 per cent moisture content ${ }^{3}$ (based on the dry weight of the wood), it is found that many timbers show measurable shrinkage at much higher moisture contents than those indicated by method $(b)$.

Other research ${ }^{4}$ at this Laboratory, which required the vapour pressure isothermal of Sitka spruce flour above 95 per cent relative humidity, showed that, on adsorption, moisture contents of about 35-40 per cent were attained before saturation was reached, which considerably exceeds the figure quoted above.

Desorption, on the other hand, showed a measurable drop of about 0.4 per cent in relative humidity on a slight drying from moisture contents as high as 90 per cent, the effect probably persisting up to even higher values. Others ${ }^{5}$ have noticed that the loop does not close at the adsorption saturation value, but have not investigated higher moisture contents. Thus there is no well-defined f.s.p., and there may well be a large moisture content hysteresis at the saturation value itself, which suggests that the shrinkages observed at high moisture contents are associated with the drop in vapour pressure found on the desorption curve.

The discrepancy between the f.s.p. obtained from method $(b)$ and that from the adsorption isothermal may be accounted for by the compression which, opposing the swelling presure of the wood, raises its vapour pressure ${ }^{6}$, thus bringing to saturation a sample of 25 per cent moisture content that was initially unsaturated. In support of this view, samples of Sitka spruce of higher strength in compression are found to show a lower apparent fibre saturation point ${ }^{2}$.

Plotting the observed shrinkage against swelling pressure calculated from the desorption curve shows a decreasing strain stress ratio on drying, corresponding to the decrease of compressibility of wood which is already well known below 25 per cent moisture content.

WILFRED W. Barkas.

Forest Products Research Laboratory, Princes Risborough.

\footnotetext{
${ }^{1}$ Chaplin, New Intl. Assn. of Testing Materials, 1931, Zurich.

${ }^{2}$ Wilson, U.S. Dept. of Agr. Bulletin No. 282, March 1932

${ }^{3}$ Unpublished data by F.P.R.L. on Sitka Spruce.

- Barkas, Nature, 130, 699; 1932.

srquhart and Williams, Shirley Inst. Mem., 3, 197 ; 1924.

- Katz, Koll. Chem. Beih, 9, 1; 1917.
}

\section{The Smell Emitted by Seaweeds}

THE offensive odour given off from masses of rotting seaweed which occasionally accumulate on the shore is a not unfamiliar phenomenon of the seaside. There can be little doubt that an important constituent of the smell is sulphuretted hydrogen produced perhaps in part by the putrefactive reduction of the ethereal sulphates which form so marked a feature of many marine algæ.

Belonging to a somewhat different category is the particularly unpleasant smell reminiscent of phosphorus given off on drying certain members of the genus Polysiphonia. I have recently been able to identify methyl sulphide as the odoriferous principle in this case. The origin of this substance is less easy to account for and investigations directed towards the elucidation of this question are in progress. Preliminary experiments would suggest that methyl sulphide is a product of modified vital activity rather 